\title{
Learning about ozone depletion
}

\author{
Paul J. Crutzen • Michael Oppenheimer
}

Received: 12 January 2007 / Accepted: 13 December 2007 / Published online: 14 March 2008

(C) The Author(s) 2008

\begin{abstract}
Stratospheric ozone depletion has been much studied as a case history in the interaction between environmental science and environmental policy. The positive influence of science on policy is often underscored, but here we review the photochemistry of ozone in order to illustrate how scientific learning has the potential to mislead policy makers. The latter may occur particularly in circumstances where limited observations are combined with simplified models of a complex system, such as may generally occur in the global change arena. Even for the well-studied case of ozone depletion, further research is needed on the dynamics of scientific learning, particularly the scientific assessment process, and how assessments influence the development of public policy.
\end{abstract}

\section{Introduction}

The resolution of the problem of ozone depletion has become a touchstone for analysis of environmental policymaking on global issues (Parson 2003; Christie 2001). Much attention has been paid to the forces behind the development of international agreements and domestic regulation (Benedick 1998; Barrett 2003), as well as the role played by evolution of scientific understanding (Rowland 1989, 2006; Parson 2003). Among the issues that

P. J. Crutzen

Department of Atmospheric Chemistry, Max Planck Institute for Chemistry, P.O. Box 3060, 55020 Mainz, Germany

M. Oppenheimer $(\bowtie)$

Department of Geosciences, Princeton University, Princeton, NJ 08544, USA

e-mail: omichael@princeton.edu

M. Oppenheimer

Woodrow Wilson School of Public and International Affairs, Princeton University, Princeton, NJ 08544, USA 
have been explored in depth are: particular features that led to the success of the Montreal Protocol and successor agreements, other factors that brought about the rapid appearance of chemicals, technologies and industrial processes that substitute for ozone-depleting halocarbons (Anderson and Madhava Sarma 2002), the interplay among scientific developments, scientific assessment, domestic regulation, international negotiation, and technological innovation, and the activities of various governmental and private interests (Parson 2003; Benedick 1998; Hammitt and Thompson 1997). Some analyses have compared the Montreal and Kyoto Protocols and the political, technological, and economic circumstances surrounding their development and implementation (Barrett 2003). A key motivation has been the search for insights that could facilitate reaching similarly favorable outcomes on other environmental problems.

Although the role played by governmental and intergovernmental scientific assessments such as those of the US National Academy of Sciences and the World Meteorological Organization has been emphasized favorably again and again, relatively little attention has been paid to the limits of scientific learning (and even misjudgments) as revealed in assessments, and how these may have affected policy makers. In the quest for encouraging lessons, some of the more challenging aspects of learning have been overlooked. Oppenheimer et al. (2008, in this issue) have identified four cases in the global change arena where learning pathways provided misleading information to policy makers at a time when key policy decisions were being made. Ozone depletion provides one such example. The other cases include assessment of the stability of the West Antarctic ice sheet, and population and energy projection. Structural errors in models used to provide policyrelevant information are implicated in each case, and, considering the importance of model projections in global change assessments, the phenomenon may be much more widespread.

In this article, we review the history of learning about ozone depletion with the aim of understanding the limits of the scientific learning process as it applies in the global change arena: how new understanding may ultimately prove incorrect and how the consensus view embodied in assessments can sometimes overshadow important uncertainties.

We focus neither on the dynamics of the assessment process itself, nor on its utility. The latter has been covered extensively elsewhere (Mitchell et al. 2006), while the former has not been much explored. A key conclusion is that in-depth review of assessment processes would be timely, perhaps in the form of case studies, in order to better judge their efficacy.

This article is narrowly focused and it does not present a full review of ozone science (see Solomon 1999; Rowland 2006; WMO 2006). Rather, we focus on certain aspects of ozone photochemistry that illustrate why learning sometimes leads to the wrong conclusions on the part of scientists, and has the potential to mislead policy makers. The interplay of theory, experiment, and observation is examined, and lessons are drawn for learning about other areas of global change.

The extent to which errant scientific beliefs (or newly acquired true beliefs) actually influenced decisions on policy is not clear cut in any of the cases discussed by Oppenheimer et al. (2008, in this issue) due to the multiplicity of factors affecting decision makers. Particularly in the case of ozone depletion, there is controversy over this question which we explore below. Nevertheless, this case illuminates the risks in consensus assessments, and underscores the need for a broader approach to uncertainty than is commonly practiced, especially in situations where science and policy are developing contemporaneously. Even for this well-studied case, we conclude that further research is needed in two key areas: 1) the dynamics of scientific learning, particularly the scientific assessment process; and, 2) how the outcomes of these assessments influenced the development of public policy. 


\section{Evolution of ozone depletion science}

\subsection{The unperturbed atmosphere}

The first theory about stratospheric ozone stems from the English scientist Sidney Chapman. In 1930, he postulated that ozone is formed by the photolysis of $\mathrm{O}_{2}$ at wavelengths shorter than $240 \mathrm{~nm}$

$$
\mathrm{R} 1 \mathrm{O}_{2}+\mathrm{h} v \rightarrow 2 \mathrm{O},
$$

immediately followed by the recombination reaction

$$
\mathrm{R} 2 \mathrm{O}+\mathrm{O}_{2}+\mathrm{M} \rightarrow \mathrm{O}_{3}+\mathrm{M},
$$

where $\mathrm{M}$ is any mediating air molecule, in practice $\mathrm{N}_{2}$ and $\mathrm{O}_{2}$. To balance the production of ozone, Chapman proposed the reactions

$$
\begin{array}{ll}
\mathrm{R} 3 & \mathrm{O}_{3}+\mathrm{h} v \rightarrow \mathrm{O}+\mathrm{O}_{2}(\lambda<1140 \mathrm{~nm}) \\
\mathrm{R} 4 & \mathrm{O}+\mathrm{O}_{3} \rightarrow 2 \mathrm{O}_{2}
\end{array}
$$

Although no direct upper atmosphere measurements were available in 1930, Chapman (1930) based his theory a) on ground-based optical measurements, showing that most ozone was located in the stratosphere and b) optical nighttime airglow measurements in the upper atmosphere of vibrationally excited $\mathrm{OH}^{*}$, which is produced by the reaction $\mathrm{H}+\mathrm{O}_{3} \rightarrow$ $\mathrm{OH}^{*}+\mathrm{O}_{2}$.

Until the middle of the 1960s it was generally believed that reactions R1-R4 were sufficient to explain the ozone distribution in the stratosphere. These reactions cannot be influenced by human activity. Improved measurements of the rate coefficients of the reactions R2 and R4, using greater care and better techniques, proved that an imbalance existed between ozone production and destruction and showed that additional reactions were needed to complete the photochemical scheme. In particular, two reactions

$$
\begin{array}{ll}
\text { R5 } & \mathrm{O}_{3}+\mathrm{OH} \rightarrow \mathrm{HO}_{2}+\mathrm{O}_{2} \\
\text { R6 } & \mathrm{O}_{3}+\mathrm{HO}_{2} \rightarrow \mathrm{OH}+2 \mathrm{O}_{2}
\end{array}
$$

with the net result $2 \mathrm{O}_{3} \rightarrow 3 \mathrm{O}_{2}$, were postulated to provide the additional ozone loss in the stratosphere. $\mathrm{OH}$ is mainly produced by photolysis of ozone

$$
\mathrm{R} 7 \quad \mathrm{O}_{3}+\mathrm{h} v(\leq 400 \mathrm{~nm}) \rightarrow \mathrm{O}^{*}+\mathrm{O}_{2}
$$

when followed by

$$
\mathrm{R} 8 \mathrm{O}^{*}+\mathrm{H}_{2} \mathrm{O} \rightarrow 2 \mathrm{OH}
$$

where $\mathrm{O}^{*}$ is an electronically excited $\mathrm{O}$ atom with sufficient energy to break the $\mathrm{H}_{2} \mathrm{O}$ bond.

When these reactions were postulated in the 1960s, the reaction coefficients R5 and R6 had not been measured in the laboratory yet and instead were chosen to explain the measured ozone concentrations. Later it was shown that the rates of these reactions were actually far too small at the appropriate altitudes to provide the ozone balance. Following a search for other alternatives, Crutzen (1970) postulated for purely scientific reasons, unrelated to any particular anthropogenic effect, that better agreement between production 
and destruction of ozone could be provided by a reaction cycle involving $\mathrm{NO}$ and $\mathrm{NO}_{2}$ as catalysts:

$$
\begin{aligned}
& \mathrm{R} 9 \mathrm{NO}+\mathrm{O} 3 \rightarrow \mathrm{NO}_{2}+\mathrm{O}_{2} \\
& \mathrm{R} 10 \quad \mathrm{NO}_{2}+\mathrm{O} \rightarrow \mathrm{NO}+\mathrm{O}_{2} \\
& \text { Net } \mathrm{O}+\mathrm{O}_{3} \rightarrow 2 \mathrm{O}_{2},
\end{aligned}
$$

with the catalyst NO coming from the reaction

$$
\mathrm{R} 11 \mathrm{O}^{*}+\mathrm{N}_{2} \mathrm{O} \rightarrow 2 \mathrm{NO} .
$$

Nitrous oxide $\left(\mathrm{N}_{2} \mathrm{O}\right)$ largely emanates from the Earth's surface as one of the products of the global biochemical nitrogen cycle. Indeed we now know that, under natural conditions, this catalytic cycle is the main one providing the required balance between ozone production and destruction in most of the stratosphere (see Crutzen 1996; Solomon 1999; Rowland 2006 for a comprehensive review of these developments). The importance of these additions to the photochemistry was confirmed by observations of ozone decreases following production of $\mathrm{NOx}$ (nitrogen oxides, $\mathrm{NO}$ and $\mathrm{NO}_{2}$ ) during solar proton events (Crutzen et al. 1975, Heath et al. 1977).

It is important to note that the hydrogen and nitrogen oxides interfere with one another, for instance through the formation and destruction of gas phase nitric acid, $\mathrm{HNO}_{3}$,

$$
\begin{array}{ll}
\mathrm{R} 12 & \mathrm{NO}_{2}+\mathrm{OH}+\mathrm{M} \rightarrow \mathrm{HNO}_{3}+\mathrm{M} \\
\mathrm{R} 13 & \mathrm{HNO}_{3}+\mathrm{h} v \rightarrow \mathrm{OH}+\mathrm{NO}_{2} \\
\mathrm{R} 14 & \mathrm{OH}+\mathrm{HNO}_{3} \rightarrow \mathrm{H}_{2} \mathrm{O}+\mathrm{NO}_{3}
\end{array}
$$

or via the reaction

$$
\mathrm{R} 15 \quad \mathrm{HO}_{2}+\mathrm{NO} \rightarrow \mathrm{NO}_{2}+\mathrm{OH}
$$

Consideration of these hybrid reactions in photochemical schemes thus leads to a decrease in the concentrations of the $\mathrm{OH}, \mathrm{HO}_{2}, \mathrm{NO}$, and $\mathrm{NO}_{2}$ catalysts, thereby protecting ozone from otherwise larger destruction.

Additional ozone destruction takes place with $\mathrm{Cl}$ and $\mathrm{ClO}$ acting as catalysts (as well as analogous reactions involving bromine):

$$
\begin{array}{ll}
\mathrm{R} 16 & \mathrm{Cl}+\mathrm{O}_{3} \rightarrow \mathrm{ClO}+\mathrm{O}_{2} \\
\mathrm{R} 17 & \mathrm{ClO}+\mathrm{O} \rightarrow \mathrm{Cl}+\mathrm{O}_{2} \\
\text { Net } & \mathrm{O}+\mathrm{O}_{3} \rightarrow 2 \mathrm{O}_{2}
\end{array}
$$

Further reactions to be considered are formation and destruction of hydrochloric acid, $\mathrm{HCl}$ and chlorine nitrate, $\mathrm{ClONO}_{2}$, by reactions:

$$
\begin{array}{ll}
\mathrm{R} 18 & \mathrm{Cl}+\mathrm{CH}_{4} \rightarrow \mathrm{CH}_{3}+\mathrm{HCl} \\
\mathrm{R} 19 & \mathrm{HCl}+\mathrm{OH} \rightarrow \mathrm{Cl}+\mathrm{H}_{2} \mathrm{O} \\
\mathrm{R} 20 & \mathrm{ClO}+\mathrm{NO}_{2}+\mathrm{M} \rightarrow \mathrm{ClONO}_{2}+\mathrm{M} \\
\mathrm{R} 21 & \mathrm{ClONO}+\mathrm{h} v \rightarrow \mathrm{Cl}+\mathrm{NO}_{3}, \text { or } \mathrm{ClO}+\mathrm{NO}_{2} \\
\mathrm{R} 22 & \mathrm{ClO}+\mathrm{NO} \rightarrow \mathrm{Cl}+\mathrm{NO}_{2}
\end{array}
$$


Under natural conditions, the stratospheric chlorine source is provided by oxidation of methyl chloride $\left(\mathrm{CH}_{3} \mathrm{Cl}\right)$ which is believed to originate in metabolic emissions from algae and soils.

\section{$\mathrm{R} 23 \mathrm{CH}_{3} \mathrm{Cl}+\mathrm{OH} \rightarrow$ via many steps $\rightarrow \mathrm{HCl}, \mathrm{ClONO}_{2}, \mathrm{Cl}, \mathrm{ClO}$, and others.}

$\mathrm{HCl}$ and $\mathrm{ClONO} 2$ have relatively long lifetimes at altitudes where most of the ozone depletion was originally thought to occur before the discovery of the ozone hole, i.e., above $25 \mathrm{~km}$. As a result, reactions R18 and R20 protect ozone from otherwise larger loss by the aforementioned catalytic reactions involving $\mathrm{NO}$ and $\mathrm{NO}_{2}$, and $\mathrm{Cl}$ and $\mathrm{ClO}$. Accordingly, $\mathrm{ClONO} 2$ and $\mathrm{HCl}$ were termed "reservoir species".

\subsection{Anthropogenic effects}

The original Chapman reactions permit no influence of human activities on stratospheric ozone. However, human activities cause the emissions of various progenitors of $\mathrm{ClO}, \mathrm{BrO}$, and $\mathrm{NO}_{\mathrm{x}}$, through which an anthropogenic effect on ozone occurs. The first concern about stratospheric ozone loss involved the potential for emissions from supersonic aircraft, initially focusing on water vapour and reactions R5 and R6 (Harrison 1970; Dotto and Schiff 1978), and later NO (Johnston 1971; Crutzen 1971). By the mid-1960s, plans were afoot for a fleet of several hundreds of these aircraft, flying in the stratosphere near $20 \mathrm{~km}$ altitude. In addition, concern arose because fuel combustion from rockets powering the early space shuttle was identified as a source of chlorine (Stolarski and Cicerone 1974). Eventually, other anthropogenic sources of stratospheric gases, including $\mathrm{H}_{2} \mathrm{O}, \mathrm{N}_{2} \mathrm{O}$, and especially the chlorofluorocarbon gases (Molina and Rowland 1974) were identified. These would lead to the production of $\mathrm{HO}_{\mathrm{x}}, \mathrm{NO}_{\mathrm{x}}, \mathrm{ClO}_{\mathrm{x}}$, which destroy ozone by the catalytic reactions shown above. Due to interactions between the hydrogen, nitrogen, and chlorine families, the chemistry of the stratosphere is complex with many feedbacks as illustrated in Fig. 1.

To make predictions of ozone loss by human activities, individual reactions were simulated in laboratory experiments and the resulting rate coefficients were included in photochemical models. Many reaction rate coefficients were difficult to measure, so the results of the laboratory simulations were often very inaccurate, sometimes by orders of magnitude, leading to high variability in estimated ozone depletion (see Crutzen 1996). Over time, much new science had to be created. Early modelling efforts suffered not only because laboratory determinations of rate coefficients were in need of frequent correction, but also because atmospheric measurements of reactive radicals were very difficult so that observational constraints on models were very loose. For example, before 1985, ozone depletion had not yet been observed, and atmospheric concentrations of key intermediate species in the chemical scheme, such as $\mathrm{OH}, \mathrm{ClO}, \mathrm{HNO}_{3}, \mathrm{NO}$, and $\mathrm{NO}_{2}$ could not be measured with sufficient accuracy to test the validity of the models at the altitudes and latitudes in the stratosphere where ozone depletion was later shown to be occurring.

Figure 2 shows calculated ozone depletion at steady-state (far in the future) by continued injections of $\mathrm{NO}_{\mathrm{x}}$ by supersonic aircraft and by fixed emission of chlorofluorocarbon gases. In order to indicate the effect of learning about photochemistry over time, results are shown (using a figure created and updated over the period by Donald Wuebbles) based on a single one-dimensional model with successive improvements in the kinetic scheme. Interestingly, estimated losses of ozone by these anthropogenic sources were negatively correlated. When $\mathrm{NO}_{\mathrm{x}}$ catalysis was predicted to result in larger ozone depletion, the opposite was true for 


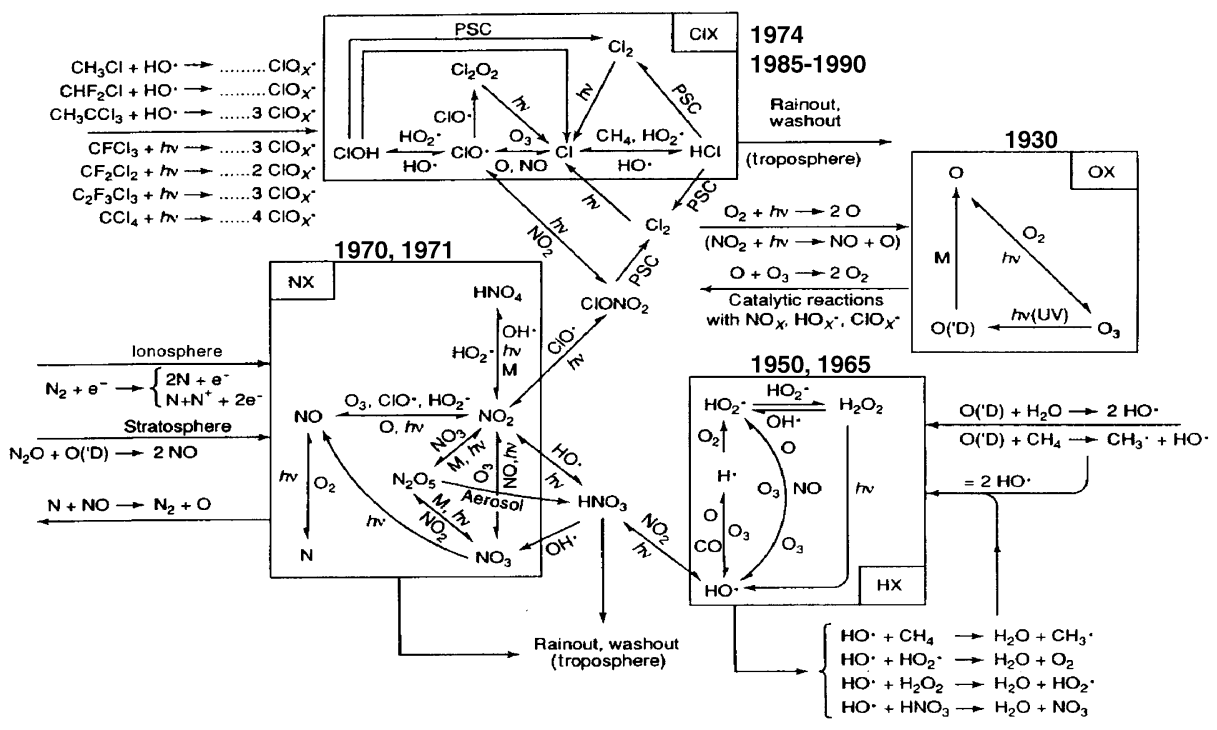

Fig. 1 Schematic presentation of the chemical interactions in the stratosphere. Not included are the bromine compounds, which likewise play a significant role in stratospheric ozone depletion. PSC $=$ polar stratospheric clouds. The Chapman reaction ( $O X$ in figure) where proposed by Chapman (1930). To obtain better agreement between production and destruction of ozone, $\mathrm{HO}_{\mathrm{x}}$ reactions were introduced in 1950 for the mesosphere and in 1965 in the stratosphere. However, these reactions were not sufficient. In 1970, catalysis by $\mathrm{NO}_{\mathrm{x}}$ was postulated and it was proposed that $\mathrm{NO}_{\mathrm{x}}$ from supersonic aircraft could destroy ozone. Ultimately, it was shown that the main anthropogenic loss of ozone resulted from atmospheric emission of CFC gases, as proposed by Molina and Rowland (1974). The importance of heterogeneous reactions on ice particles was understood in the latter half of the $1980 \mathrm{~s}$, following the discovery of the "ozone hole" by Farman et al (1985). Note that this diagram contains many more reactions than discussed in the text, although some reactions, such as analogs to R16 and R17 involving bromine, have been omitted to enhance clarity of the figure

$\mathrm{ClO}_{\mathrm{x}}$, and vice versa. One of the reasons for this odd behavior is the different impact of $\mathrm{OH}$ chemistry on the concentrations of $\mathrm{NO}_{\mathrm{x}}$ and $\mathrm{ClO}_{\mathrm{x}}$. When estimated reaction coefficients led to higher calculated $\mathrm{OH}$ concentrations, then, through $\mathrm{HNO}_{3}$ formation by reaction $\mathrm{R} 12$, $\mathrm{NO}_{\mathrm{x}}$ concentration and calculated ozone losses by the $\mathrm{NO}_{\mathrm{x}}$ catalytic cycle went down; simultaneously, projected availability of $\mathrm{Cl}$ via reaction $\mathrm{R} 19$ and stimulation of ozone depletion by the ClOx cycle (R16 and R17) went up. The opposite behaviour occurred when $\mathrm{OH}$ concentrations in simulations declined.

Depletion projected during the initial learning process (1974-1985) was dominated by consideration of additional reactions and, eventually, improved determinations of rate coefficients of gas phase reactions in the laboratory (see NAS 1984; WMO 1986 for discussion of specific measurements that caused changes in these results over time). At the time, the largest ozone depletions were expected to occur above about $25 \mathrm{~km}$ altitude. Projected depletion grew smaller for an extended period, that is, departed further from the values later shown to be correct (Oppenheimer et al. (2008, in this issue), Fig. 1).

However, the largest shift in observing and understanding of ozone occurred with the discovery of the Antarctic springtime "ozone hole" (Farman et al 1985), which could not be explained by the gas phase reactions discussed so far. It became apparent that heterogeneous chemical reactions on the surfaces of stratospheric ice (or nitric acid trihydrate) particles (Sato and Rowland 1984; Crutzen and Arnold 1986; Solomon et al. 1986; Toon et al. 1986), at 


\section{CALCULATED OZONE - COLUMN CHANGE TO STEADY STATE}

FOR TWO STANDARD ASSUMED PERTURBATIONS

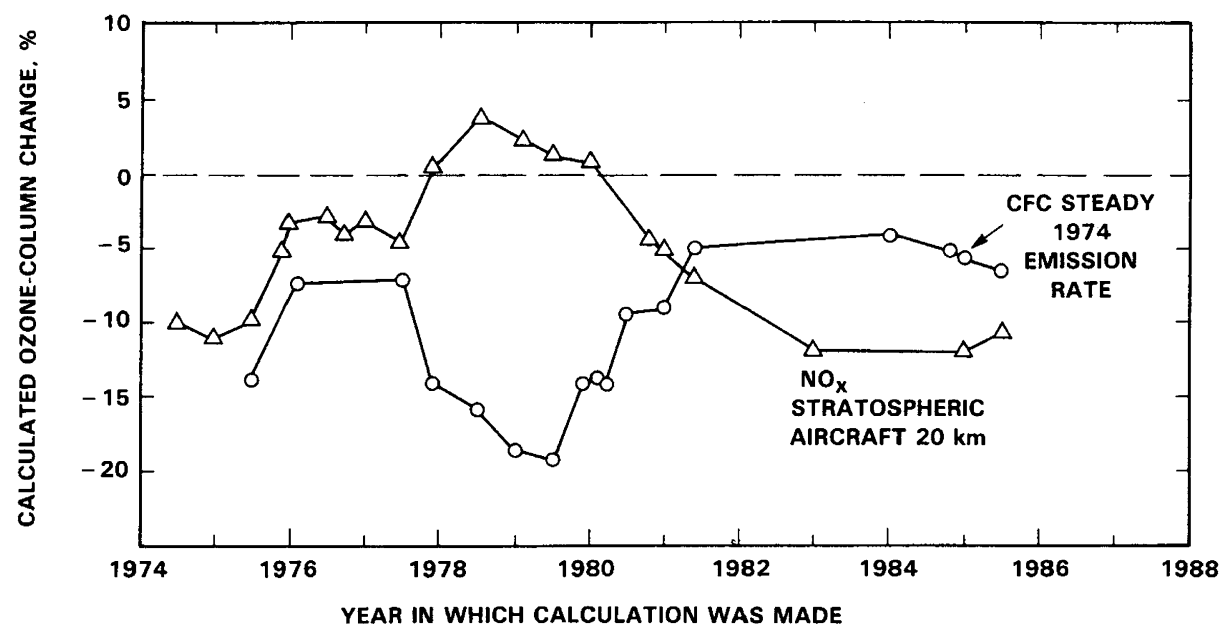

Fig. 2 Calculated ozone-column change to steady state for two standard assumed perturbations: (a) 2,000 molecules $\mathrm{cm}^{-3} \mathrm{~s}^{-1}$ of nitric oxide emitted over $1 \mathrm{~km}$ interval centered at $20 \mathrm{~km}$ (originally based on a hypothetical, large fleet of stratospheric aircraft (triangles)); (b) CFC-11 and CFC-12 emitted continuously at 1974 rate (circles). These calculations were made at Lawrence Livermore Laboratory over an 11-year period using laboratory simulated (initially often incorrect) reaction rate coefficients and other photochemical parameters, eddy diffusion functions, and boundary conditions (from WMO 1986)

temperatures below about $-75^{\circ} \mathrm{C}$ (which occur below $25 \mathrm{~km}$ altitude and at high latitudes), could lead to "chlorine activation" by disruption of the aforementioned reservoirs. Heterogeneous reactions generally had been disregarded, in the belief that they were not needed to explain the large-scale distribution of ozone in the stratosphere (and ozone depletion had not yet been observed). Also, laboratory measurements of the rates of heterogeneous reactions are extremely difficult, and early attempts either failed or were carried out under conditions not pertinent to the cold conditions at high latitudes (Molina et al. 1985).

One such heterogeneous reaction which empties the chlorine nitrate reservoir is (Molina et al. 1987)

$$
\mathrm{R} 24 \mathrm{ClONO}_{2}+\mathrm{HCl} \rightarrow \mathrm{Cl}_{2}+\mathrm{HNO}_{3}
$$

When sunlight returns to Antarctica in late winter/early spring, a series of chemical reactions then lead to $\mathrm{Cl}$ production, for example

$$
\mathrm{R} 25 \mathrm{Cl}_{2}+\mathrm{h} v \rightarrow 2 \mathrm{Cl}
$$

followed by ozone loss via the catalytic reaction chain (Molina and Molina 1987)

$$
\begin{array}{ll}
\mathrm{R} 16 & 2\left(\mathrm{Cl}+\mathrm{O}_{3} \rightarrow \mathrm{ClO}+\mathrm{O}_{2}\right) \\
\mathrm{R} 26 & \mathrm{ClO}+\mathrm{ClO}+\mathrm{M} \rightarrow \mathrm{Cl}_{2} \mathrm{O}_{2}+\mathrm{M} \\
\mathrm{R} 27 & \mathrm{Cl}_{2} \mathrm{O}_{2}+\mathrm{h} v \rightarrow \mathrm{Cl}+\mathrm{Cl}+\mathrm{O}_{2} \\
\mathrm{Net} & 2 \mathrm{O}_{3} \rightarrow 3 \mathrm{O}_{2}
\end{array}
$$


with contributions $\left(\approx 30 \%\right.$ ) also coming from a mixed $\mathrm{ClO}_{\mathrm{x}}$ and $\mathrm{BrO}_{\mathrm{x}}$ catalytic cycle.

$$
\begin{array}{ll}
\mathrm{R} 28 & \mathrm{Cl}+\mathrm{O}_{3} \rightarrow \mathrm{ClO}+\mathrm{O}_{2} \\
\mathrm{R} 29 & \mathrm{Br}+\mathrm{O}_{3} \rightarrow \mathrm{BrO}+\mathrm{O}_{2} \\
\mathrm{R} 30 & \mathrm{ClO}+\mathrm{BrO} \rightarrow \mathrm{Cl}+\mathrm{Br}+\mathrm{O}_{2} \\
\text { Net } & 2 \mathrm{O}_{3} \rightarrow 3 \mathrm{O}_{2}
\end{array}
$$

$\mathrm{ClO}_{\mathrm{x}}$ and $\mathrm{BrO}_{\mathrm{x}}$ are the products of the photochemical decay of chlorine and brominecontaining industrial halocarbons, such as the chlorofluorocarbons (CFCs).

These reactions are particularly important during late winter to early spring in the Antarctic stratosphere, and, depending on temperature, in Arctic regions as well, occurring exactly in the height range where, under natural conditions, maximum ozone concentrations are found. Later, other heterogeneous reactions were shown to contribute to depletion at the midlatitudes as well.

The rate of this catalytic reaction schema depends particularly on the rate of reaction R26, so that the loss of ozone is quadratically dependent on the $\mathrm{ClO}$ concentration (Molina et al. 1987). The current anthropogenic chlorine content of the stratosphere is about seven times larger than natural (produced by reaction R23) implying that the corresponding ozone loss by chlorine catalysis under springtime polar conditions is about fifty times greater than under natural conditions. This explains the rapidity of ozone depletion, which was not predicted, but revealed by measurements. Soon after discovery of the ozone hole, airborne measurements in the stratosphere and measurements in the laboratory (Molina and Molina 1987; Molina et al. 1987) led to detailed understanding of the kinetics of the reactions which destroy ozone.

\section{Learning, ozone chemistry, and policy}

As detailed in the previous section, improvements in the photochemical scheme caused one policy-relevant measure of ozone depletion, projected depletion at steady state for constant 1974 emissions (a convenient measure of ozone sensitivity to halogens that was commonly used in assessments), to oscillate and then drift toward low values. No simulations employing current state-of-the-art photochemistry (i.e., including heterogeneous reactions) are available using such emissions levels (because international agreements reduced interest in them by precluding their occurrence). But scaling of current observations indicates that global average depletion for such emissions would actually exceed $15 \%$, comparable to some estimates made before 1980 but much higher than the values obtained from circa 1985 simulations based on more advanced gas-phase photochemistry than the pre-1980 versions (Oppenheimer et al. (2008, in this issue), Fig. 1).

There are two ways in which the behaviour of ozone sensitivity reflected in Fig. 2 may have influenced public and private decision makers before 1985, particularly in combination with reduced production of CFCs following restriction on their use in aerosol spray cans. First, the reduced magnitude of the risk may have lessened the sense of urgency toward dealing with the problem among policy makers and the public (Levy et al. 2001, p.95; Christie 2001, p. 84; Hammitt and Thompson 1997, p. 60). Legal limits on production of chlorofluorocarbons for use as aerosol propellants were taking effect and additional actions to limit production of chlorofluorocarbons were under consideration. A reduced sense of urgency arising in part from changes in the science was also reported by firms producing CFCs (and investigating potential substitute chemicals, Parson 2003, p. 123). Secondly, oscillation in projected depletion between 1974 and 1981 may have undermined 
both the credibility and urgency attached to the problem by policy makers and the general public (Benedick 1998, p.13).

Yet it would be excessive to claim that the misleading photochemical learning pathway in Fig. 2 was more than one among several factors causing delay in action to further limit production of halocarbons. Parson (2003, Ch.4) and others have argued that large depletion values projected starting in 1985 from transient scenarios based on forecast of growth in CFC production, combined with the fact of increased production after 1982, were the key influences on policy makers. Or, to state the inverse: the minimal focus in assessments before 1985 on potential for future production growth, along with the actual decrease in production from 1974 to 1982, were the key influences retarding development of regulations beyond those for aerosol propellants. Similarly, some have argued that the possibility of high ozone sensitivity revealed by the appearance of the ozone hole was a key influence on the Montreal Protocol process while others see the ozone hole's main influence as bearing on subsequent agreements (Benedick 1998).

It is the product of sensitivity of ozone photochemistry (of which steady-state depletion is one measure) and atmospheric concentration of halocarbons (a function of emissions) which determines the risk, and possibly, the perception of risk as well. Levels of photochemical sensitivity that may not seem threatening at low halocarbon concentrations could appear to pose a high risk at high concentrations. One also can pose the counterfactual argument that the likelihood of comprehensive regulation would have been higher around 1980 even with anticipation of little or no growth in future production if ozone sensitivity was believed to be as high as it ultimately proved to be. However, many political factors stood in the way of further regulation as well and it is not possible to judge how high modelled sensitivity would need to have been to overcome the latter obstacles. Likewise, one can argue that as events actually unfolded, relatively low sensitivity did not stand in the way of movement toward further regulation once high emissions were deemed plausible (Parson 2003).

Clearly, misleading assessment of either environmental sensitivity or anthropogenic forcing may influence policy. Our main point is that in the case of ozone depletion, as with other problems of global change, decision making (either to act or to refrain from action) sometimes must proceed on a faster timescale than that for resolution of such issues. Accordingly, temporarily mistaken assessment may bear long term consequences in terms of impacts (Ha-Duong et al. 2003).

Model-based misjudgements about ozone sensitivity were not corrected until the direction of the learning pathway was shifted radically by atmospheric observations of polar and midlatitude ozone depletion. Several factors caused assessments to minimize consideration of scenarios forecasting production growth (Parson 2003, pp. 77-81). But as with high ozone sensitivity, detailed consideration of such scenarios awaited the observation of actual emissions growth. From one perspective, the relative influence of each factor (sensitivity and emissions growth) is less important than the realization that assessments, as currently practiced, do not provide a satisfactory description of risk in a timely fashion because they do not sufficiently exhibit the range of plausible outcomes (Oppenheimer et al. 2007).

\section{Conclusion: lessons for future assessments}

The ozone hole was unanticipated, probably the truest surprise occurrence in global change science to date. A combination of factors, including the general dismissal of heterogeneous chemistry (Molina et al. 1985) and the scarcity and difficulty of observations in polar 
regions, played a role. Rates of heterogeneous reactions are notoriously difficult to measure. Although their importance was discounted in assessments of the problem before the late 1980s (NAS 1984; WMO 1986), interest in their possible role persisted among some scientists (Sato and Rowland 1984), particularly in light of observations suggesting ozone loss at midlatitudes (Rowland 1989; 2006), and model simulations indicating that, with arbitrarily set rates, their effect on ozone could become quite large (Wuebbles and Connell 1984). Nevertheless, only the observation of the ozone hole forced a complete reassessment of the chemical scheme. The importance of heterogeneous chemistry was reinforced by subsequent identification of larger-than-expected depletion at midlatitutdes with an unpredicted seasonal and latitudinal pattern (WMO 1988) as well as observation of depletion in the Arctic (WMO 1991) and following volcanic eruptions (Hoffman and Solomon 1989).

Taking this history as a whole, it is apparent that atmospheric observations and laboratory measurements led to key breakthroughs in theory and modelling. Some science historians have criticized the tendency to focus on "key" experiments or observations as the driving force behind revolutionary changes in science (Gilbert and Mulkay 1984). But in the case of ozone depletion, such a focus seems entirely justified. Furthermore, much of global change science shares the characteristics of the ozone problem that made a handful of observations critical to changes in theory: field measurements are sparse, and theory and models are often not well anchored. In analogy to the difficulty of measuring key intermediate atmospheric species in ozone chemistry (see above), key processes in other global change arenas, such as the ice sheets, cannot be determined due to a lack of detailed measurements in the right place at the right time, leaving models unconstrained. Furthermore, coordinated progress in measurement, observation and theory relies on bringing to bear expertise from multiple sub-specialties, a slow and difficult process (Christie 2001).

In such situations, assessments can become inordinately dependent on projections of models that are validated across a limited range of experience. A broader set of tools, such as analysis of paleoclimate analogs, and a more comprehensive assessment of uncertainties (Moss and Schneider 2000) are required to provide policy makers with the fullest range of plausible outcomes. The fact that gradual improvement in some aspects of ozone photochemistry (Fig. 2) could cause a key outcome of modelling to diverge from the right answer demonstrates the difficulties that may arise in modelling complex problems with relatively simple representations (e.g., lacking heterogeneous chemistry) that capture only part of the physical reality. There are known uncertainties and still unknown uncertainties. The latter can be most important.

Despite the extensive literature on various facets of ozone depletion, there is no fully satisfactory history of the science. It is critical that new research examine the dynamics of learning about the ozone depletion problem within a history-of-science framework in order to understand in detail why scientists acting as individuals, as well as deliberating in assessment groups, set aside heterogeneous chemistry as a potential key factor in the photochemistry of ozone before the ozone hole was discovered. One use of such research would be to design improvements in the assessment process and its handling of uncertainty. Furthermore, given the range of opinion, a more comprehensive examination of the way science and science assessments influenced the timing of regulatory policy is in order.

With implementation of the Montreal Protocol and successor agreements, chlorocarbon concentrations are declining and eventually, recovery of ozone would be expected as well. However, projecting the future of the ozone layer is complicated by the fact that Earth is now entering yet another new geophysical regime where greenhouse gas concentrations are 
increasing, causing changes in stratospheric temperature, water content, and other properties. "The high natural variability in ozone abundances, due in part to the solar cycle as well as changes in transport and temperature, could override the relatively small changes expected from the recent decrease in ozone-depleting substances. Whatever the benefits of the Montreal agreement, recovery of ozone is likely to occur in a different atmospheric environment, with changes expected in atmospheric transport, temperature and important trace gases. It is therefore unlikely that ozone will stabilize at levels observed before 1980, when a decline in ozone concentrations was first observed (Weatherhead and Andersen 2006)".

Despite more than thirty years of learning about ozone depletion, more surprises are probably in the offing.

Open Access This article is distributed under the terms of the Creative Commons Attribution Noncommercial License which permits any noncommercial use, distribution, and reproduction in any medium, provided the original author(s) and source are credited.

\section{References}

Anderson SO, Madhava Sarma K (2002) Protecting the ozone layer: the United Nations history. Earthscan Publications Ltd, London

Benedick R (1998) Ozone diplomacy: new directions in safeguarding the planet. Harvard Univ. Press, Cambridge, MA

Barrett S (2003) Environment and statecraft: the strategy of environmental treaty-making. Oxford University Press, New York

Chapman S (1930) A theory of upper atmospheric ozone. Memoirs of the Royal Meteorological Society 3:103-125

Christie M (2001) Ozone layer: a philosophy of science perspective. Cambridge Univ. Press, Cambridge, UK, New York

Crutzen PJ (1970) The influence of nitrogen oxides on the atmospheric ozone content. Q J R Meteorol Soc 96:320-325

Crutzen PJ (1971) Ozone production rates in an oxygen-hydrogen-nitrogen oxide atmosphere. J Geophys Res 76:7311-7327

Crutzen PJ (1996) My life with $\mathrm{O}_{3}, \mathrm{NO}_{\mathrm{x}}$, and $\mathrm{YZO}_{\mathrm{x}}$ compounds. Angew. Chem Angew Chem Int Ed Engl Suppl 35:1758-1777

Crutzen PJ, Arnold F (1986) Nitric acid cloud formation in the cold Antarctic stratosphere: a major cause for the springtime "ozone hole". Nature 324:651-655

Crutzen PJ, Isaksen ISA, Reid GC (1975) Solar proton events: stratospheric sources of nitric oxide. Science 189:457-459

Dotto L, Schiff H (1978) The Ozone War, Doubleday \& Co, Inc, Garden City, NY, Ch.2,3.

Farman JC, Gardiner BG, Shanklin JD (1985) Large losses of total ozone in Antarctica reveal seasonal ClOx/ NOx interaction. Nature 315:207-210

Gilbert GN, Mulkay M (1984) Experiments are the key. Isis 75:105-125

Ha-Duong M, Mégie G, Hauglustaine D (2003) A pro-active stratospheric ozone protection scenario. Global Environ Change 13:43-49

Hammitt JK, Thompson JM (1997) Protecting the ozone layer. In: Graham JD, Hartwell JK (eds) The Greening of Industry: A Risk Management Approach. Harvard Univ. Press, Cambridge, MA, pp 43-92

Harrison H (1970) Stratospheric ozone with added water vapor: influence of high-altitude aircraft. Science 170:734-736

Heath DF, Krueger AJ, Crutzen PJ (1977) Solar proton events: influence on stratospheric ozone. Science 197:886-889

Hofmann DJ, Solomon S (1989) Ozone destruction through heterogeneous chemistry following the eruption of El Chichon. J Geophys Res 94(D4):5029-5041 
Johnston HS (1971) Reduction of stratospheric ozone by nitrogen oxide catalysts from supersonic transport exhaust. Science 173:517-522

Levy MA, Cavender-Bares J, Clark W (2001) Goal and strategy formulation in the management of global environmental risks. In: The Social Learning Group, Learning to manage global environmental risks. MIT Press, Cambridge, MA Ch. 18

Mitchell RB et al (ed) (2006) In: Global environmental assessments: information and influence. MIT Press, Cambridge, MA

Molina MJ, Rowland FS (1974) Stratospheric sink for chlorofluoromethanes: chlorine atom-catalysed destruction of ozone. Nature 249:810-812

Molina LT, Molina MJ (1987) Production of chlorine oxide (Cl2O2) from the self-reaction of the chlorine oxide (ClO) radical. J Phys Chem 91:433-436

Molina LT et al (1985) An upper limit to the rate of the $\mathrm{HCl}+\mathrm{CIONO}_{2}$ reaction. J Phys Chem 89:3779-3781

Molina MJ et al (1987) Antarctic stratospheric chemistry of chlorine nitrate, hydrogen chloride, and ice: release of active chlorine. Science 238:1253-1257

Moss RH, Schneider S (2000) Uncertainties. In: Pachauri R, et al (eds) Guidance Papers on the Cross Cutting Issues of the Third Assessment Report of the IPCC. Geneva, 2000, pp 33-51

NAS (1984) Causes and effects of changes in stratospheric ozone: update 1983. Natl Acad Sci, Washington, D.C

Oppenheimer M, O'Neill BC, Webster M (2008) Negative learning. Climatic Change, DOI 10.1007/s10584008-9405-1

Oppenheimer M, O'Neill BC, Webster M, Agrawala S (2007) The limits of consensus. Science 317:15051506

Parson E (2003) Protecting the ozone layer: science and strategy. Oxford Univ. Press, Oxford, New York

Rowland FS (1989) Chlorofluorocarbons and the depletion of stratospheric ozone. Am Sci 77:36-45

Rowland FS (2006) Stratospheric ozone depletion. Philos Trans R Soc Lond B 361:769-790 DOI 10.1098/ rstb.2005.1783

Sato H, Rowland FS (1984) Paper presented at the international meeting on current issues in our understanding of the stratosphere and the future of the ozone layer, Feldafing, West Germany, 11-16 June 1984

Solomon S (1999) Stratospheric ozone depletion: a review of concepts and history. Revs Geophys 37:275-316

Solomon S, Garcia RR, Rowland FS, Wuebbles DJ (1986) On the depletion of Antarctic ozone. Nature 321:755-758

Stolarski RS, Cicerone RJ (1974) Stratospheric chlorine: a possible sink for ozone. Can J Chem 52:1610-1615

Toon $\mathrm{OB}$ et al (1986) Condensation of $\mathrm{HNO} 3$ and $\mathrm{HCl}$ in the winter polar stratosphere. Geophys Res Lett 13:1284-1287

Weatherhead EC, Andersen SB (2006) The search for signs of recovery of the ozone layer. Nature 441:39-45

WMO (1986) Atmospheric Ozone 1985, Report No. 16, p 773

WMO (1988) Report of the International Ozone Trends Panel-1988, Global Ozone Research and Monitoring Project, Report No.18, World Meteorological Organization, Geneva, 1988

WMO (1991) Scientific Assessment of Ozone Depletion, 1991, World Meteorological Organization, Global Ozone Research and Monitoring Project - Report No. 25, World Meteorological Organization, Geneva, 1991

WMO (2006) Scientific Assessment of Ozone Depletion: 2006, Executive Summay, World Meteorological Organization and UN Environment Program, Geneva, 2006

Wuebbles DJ, Connell PS (1984) Interpreting the 1D Model Calculated Nonlinearities from Chlorocarbon Perturbations. Paper presented at international workshop on current issues in our understanding of the stratosphere and the future of the ozone layer, Feldafing, Germany, 11-16 June 1984 